\title{
MộT Số YẾU TỐ LIÊN QUAN ĐẾN SUY GIẢM NHẬN THỨC Ở BÊ̂NH NHÂN TÂM THẦN PHÂN LIÊTT
}

\begin{abstract}
Đoàn Văn S $\tilde{y}^{1,3}$,
TÓM TẮT

Bệnh tâm thần phân liệt là một bệnh loạn thần nặng, có khuynh hướng tiến triển mạn tính và hay tái phát, ảnh hưởng đến chức năng nhận thức của bệnh nhân. Việc đánh giá các yếu tố nguy cơ giúp tiên lượng và lên kế hoạch điêuu trị. Mục tiêu: Tìm hiểu yếu tố liên quan đến suy giảm nhận thức ở bệnh nhân tâm thân phân liệt tại trung tâm chăm sóc và nuôi dưỡng người tâm thân Hà Nội. Đối tượng và phương pháp nghiên cứu: Nghiên cứu mồ tả cắt ngang trên 300 bệnh nhân được chẩn đoán TTPL, điêu trị tại trung tâm chăm sóc và nuôi dưỡng người tâm thần Hà Nội từ tháng 10/2020 đến tháng 03/2021, có sử dụng đánh giá lâm sàng và thang điểm đánh giá tâm thân tối thiểu (MMSE). Kết quả: Tỷ lệ suy giảm nhận thức ở bệnh nhân tâm thần phân liệt là $87,3 \%$, chủ yếu ở mức độ nhẹ. Các yếu tố giới tính nữ, trình độ học vấn dưới TPHT, không có gia đình riêng là các yểu tố liên quan đến SGNT ở bệnh nhân TTPL. Kết luận: Suy giảm nhận thức ở bệnh nhân TTPL chiếm tỷ lệ cao, cần có kế hoạch can thiệp sớm để giảm gánh nặng cho gia đình bệnh nhân và xã hội.
\end{abstract}

Tư khóa: tâm thân phân liệt, suy giảm nhận thức, yếu tố nguy cơ.

\section{SUMMARY}

FACTORS RELATED TO COGNITIVE DEFICIT IN SCHIZOPHRENIA PATIENTS

Schizophrenia is a severe, chronic and relapsing psychotic disorder that affects patients' cognitive function. The assessment of risk factors helps in prognosis and treatment planning. Objective: To study the factors related to cognitive decline in schizophrenic patients at Hanoi psychiatric care and nurturing center. Subjects and research methods: A cross-sectional descriptive study on 300 patients diagnosed with schizophrenia, treated at the Hanoi psychiatric care and nurturing center from October 2020 to March 2021. using clinical assessment and the minimal psychiatric evaluation scale (MMSE). Results: The rate of cognitive decline in schizophrenic patients was $87.3 \%$, mainly at mild level. Female gender factors, education level below schizophrenia, no family of their own are factors related to schizophrenia in schizophrenic patients. Conclusion: Cognitive decline in schizophrenic patients accounts for a high rate, it is necessary to have an early intervention plan to reduce

${ }^{1}$ Đại học Y hà Nội

${ }^{2}$ Viện Sức khỏe Tâm thần, Bệnh viện Bạch Mai

${ }^{3}$ Trung tâm chăm sóc và nuôi dướng người tâm thần Hà Nội

Chịu trách nhiệm chính: Đoàn Văn Sỹ

Email: doanvansy690@gmail.com

Ngày nhân bài: 24.6.2021

Ngày phản biên khoa hoc: 20.8.2021

Ngày duyệt bài: 27.8.2021 the burden on the patient's family and society.

Keywords: schizophrenia, cognitive deficit, risk factor

\section{I. ĐẶT VẤN ĐỀ}

Bệnh tâm thần phân liệt là một bệnh loạn thân nặng ảnh hưởng đến hơn 20 triệu người trên thế giới với tỷ lệ mắc mới mỗi năm là 1,5/10.000 người [1]. Theo báo cáo gánh nặng bệnh tật toàn cầu (the global burden of disease) nằm 2016 của Tổ chức Y tế Thế giới, bệnh tâm thân phân liệt tuy chiếm tỷ lệ thấp so với nhiêu mặt bệnh khác nhưng đứng thứ 12 về gánh nặng bệnh tật toàn câu [2]

Đa số các nhà khoa học đều đã công nhận rằng có sự suy giảm nhận thức nhiều mức độ ở những bệnh nhân TTPL và suy giảm nhận thức được coi là một đặc điểm chính của bệnh và là gánh nặng lớn cho bản thân bệnh nhấn và gia đình. Năm 1998, Heinrichs và Zakzanis đã tiến hành một nghiên cứu tổng quan bao gồm 204 nghiên cứu về nhận thức trong TTPL, cho biết 70 - 80\% bệnh nhân TTPL có ít nhất là suy giảm nhận thức nhẹ [3], [4]. Không có mẫu hình suy giảm nhận thức chung duy nhất cho tất cả các bệnh nhẩn TTPL, nhưng những chức năng bị suy giảm thường gặp nhất là chú ý, trí nhớ công việc, học hình ành và lời nói, tốc độ tâm thân vận động, và khả năng thực hiện nhiệm vụ.

Việc tìm hiểu các yếu tố nguy cơ của suy giảm nhận thức ở bệnh nhân TTPL có giá trị trong quá trình điêu trị, tiên lượng từ đó có các biện pháp chăm sóc phug hợp. Chính vì những lý do trên chúng tôi tiến hành nghiên cứu với mục tiêu sau: Tìm hiểu yếu tố liên quan đến suy giảm nhận thức ở bệnh nhân tâm thân phân liệt tại trung tâm chăm sóc và nuôi dưỡng người tâm thân Hà Nội.

\section{II. ĐỐI TƯỢNG VÀ PHƯƠNG PHÁP NGHIÊN CỨU}

1. Đối tượng.Tất cả bệnh nhân đáp ứng đủ tiêu chuẩn chẩn đoán xác định là Tâm thân phân liệt theo ICD-10 đang điểu trị tại Trung tâm chăm sóc và nuôi dưỡng người tẩm thân Hà Nội

2. Phương pháp: mô tả cắt ngang, lấy mẫu toàn bộ.

2.1. Công cụ nghiên cứu. Bệnh án nghiên cứu thăm khám các đặc điểm lâm sàng trên bệnh nhân.

Sử dụng bảng câu hỏi MMSE đánh giá mức độ suy giảm nhận thức trên bệnh nhân. 
Các yễu tố nhân khẩu hoc, tiền sử bênh và tình trạng bệnh nhân được khai thác theo mẫu bệnh án được thiết kế.

2.2. Phương pháp thu thâp thông tin. Người chăm sóc và bệnh nhân được phỏng vấn và khám bởi nghiên cứu viên là bác sĩ chuyên khoa Tâm thần theo bệnh án mẫu. Thời gian thu thâpp từ tháng 9 năm 2020 đến tháng 3 năm 2021.

3. Xử lý số liệu. Số liệu được thu thập và xử lý trên phần mềm thống kê SPSS 25.0.

4. Đạo đức nghiên cứu. Chúng tôi thông báo mục đích nghiên cứu với gia đình bệnh nhân và chỉ đưa vào danh sách nghiên cứu khi được sự đồng ý của họ. Tất cả các thông tin cá nhân và bệnh tật được giữ bí mật. Nghiên cứu không can thiệp vào quá trình điều trị của bệnh nhân.

\section{KẾT QUẢ NGHIÊN CỨU}

\section{1. Đặc điểm nhân khẩu học}

Bảng 1. Đặc điểm nhân khẩu học của bênh nhân

\begin{tabular}{|c|c|c|}
\hline Đặc điếm & $\mathbf{n}$ & Tỷ lệ \\
\hline Giới tính: Nam & 220 & 73,3 \\
\hline Nữ & 80 & 26,7 \\
\hline Nhóm tuối: $<30$ & 10 & 3,3 \\
\hline $30-39$ & 50 & 16,7 \\
\hline $40-49$ & 88 & 29,3 \\
\hline $50-59$ & 109 & 36,3 \\
\hline$\geq 60$ & 43 & 14,3 \\
\hline Khu vực sống: Nông thôn & 172 & 57,3 \\
\hline Thành thi & 127 & 42,3 \\
\hline Khác & 1 & 0,3 \\
\hline Trình độ học vấn: Thất học & 25 & 8,3 \\
\hline Tiếu học & 71 & 23,7 \\
\hline THCS & 110 & 36,7 \\
\hline THPT & 86 & 28,7 \\
\hline Đại học và sau đại học & 8 & 2,7 \\
\hline \multicolumn{3}{|l|}{ Tình trạng hôn nhân } \\
\hline Độc thân & 227 & 75,7 \\
\hline Có gia đình & 48 & 16,0 \\
\hline Sống cùng: Bố mẹ & 226 & 75,3 \\
\hline Gia đình riêng & 52 & 17,3 \\
\hline Người quen & 17 & 5,7 \\
\hline Một mình & 5 & 1,7 \\
\hline Hồ trợ nhà nước: Không & 65 & 21,7 \\
\hline Có & 235 & 78,3 \\
\hline Kinh tế gia đình: Nghèo & 136 & 45,3 \\
\hline Trung bình & 157 & 52,3 \\
\hline Khá giả & 7 & 2,3 \\
\hline
\end{tabular}

\section{Nhận xét:}

- Giới: Trong số đối tượng tham gia nghiên cứu, đối tượng chủ yếu là nam, chiếm 73,3\%.

- Tuổi: Nhóm tuổi phổ biến trong nghiên cứu là $50-50$ với $36,3 \%$, tiếp theo là nhóm 40-49 tuổi với tỷ lệ 29,3\%, nhóm ít nhất là dưới 30 tuổi.

- Khu vực sống: đối tượng nghiên cứu chủ yếu ở nông thôn chiếm $57,3 \%$.

- Trình đô hoc vấn: đa số ở mức THCS chiếm $36,7 \%$, sau đó là THPT chiếm $28,7 \%$, tiểu học chiếm 23,7\%, nhóm học Đại học và Sau đại học chiếm ít nhất với $2,7 \%$.

- Tình trang hôn nhân: nhóm có gia đình chỉ chiếm $16 \%$ trong khi nhóm độc thân chiếm tỷ lệ cao với 75,7\%. Phần lớn đang sống cùng bô mẹ với tỷ lệ 75,3\%, số bệnh nhân sống cùng gia đình riêng chỉ chiếm 17,3, số lượng sống cùng người quen chiếm $5,7 \%$, sống một mình chiếm 1,7\%.

- Hỗ trợ của nhà nước. Trong nhóm bệnh nhân tham gia nghiên cứu tại trung tâm có tới 78,3\% nhân được sự hỗ trơ từ nhà nước. Cũng trong nhóm này tỷ lệ bệnh nhân nghèo chiếm $45,3 \%$, trung bình chiếm $52,3 \%$, nhóm khá giả chỉ chiếm 2,3\%.

\section{2. Đăc điểm lâm sàng chung bênh TTPL}

Bảng 2. Đặc điểm lâm sàng chung bệnh TTPL

\begin{tabular}{|c|c|c|}
\hline Đăc điếm & $\mathbf{n}$ & Tỷ lê \\
\hline Thế bệnh hiện tại: F20.0 & 59 & 19,7 \\
\hline F20.1 & 1 & 0,3 \\
\hline F20.3 & 6 & 2,0 \\
\hline F20.5 & 230 & 76,7 \\
\hline F20.6 & 4 & 1,3 \\
\hline Ȧo giác: Không có & 276 & 92,0 \\
\hline Áo thanh & 23 & 7,7 \\
\hline Áo thị & 1 & 0,3 \\
\hline Hoang tưởng: Không & 276 & 92,0 \\
\hline HT bị hại & 6 & 2,0 \\
\hline HT bị tội & 2 & 0,7 \\
\hline HT bị theo dõi & 3 & 1,0 \\
\hline HT liền hề & 11 & 3,7 \\
\hline HT bi chi phối & 2 & 0,7 \\
\hline Khí săc: Bình thần & 177 & 59,0 \\
\hline Tăng & 17 & 5,7 \\
\hline Giảm & 106 & 35,3 \\
\hline Lo âu: & 279 & 93,0 \\
\hline Có & 21 & 7,0 \\
\hline Hoạt động có ý chí: Bình thường & 87 & 29,0 \\
\hline Tăng & 2 & 0,7 \\
\hline Giảm & 211 & 70,3 \\
\hline Rối loạn ăn uống: Không & 17 & 5,7 \\
\hline Có & 283 & 94,3 \\
\hline Rối loạn giấc ngủ: Không & 18 & 6,0 \\
\hline Có & 282 & 94,0 \\
\hline
\end{tabular}

Nhận xét: Trong số 300 bệnh nhân tâm thần phân liêt tham gia nghiên cứu, mã bênh chẩn đoán chính là F20.5 với 230 bênh nhẩn chiếm $76,7 \%$, sau đó là mã F20.0 chiếm 19,7\%. 11 
bệnh nhân còn lại được chẩn đoán với các mã F20.1, F20.3, F20.6 chiếm tỷ lệ thấp.

Số bệnh nhân có ảo giác tại thời điểm thăm khám là 24 bệnh nhân chiếm $8 \%$, trong đó 7,7\% có ảo thanh và $0,3 \%$ có ảo thị.

Số bệnh nhân có hoang tưởng tại thời điểm thăm khám là 24 bệnh nhân chiếm $8 \%$, trong đó phổ biến lần lượt là là hoang tưởng liên hệ $(3,7 \%)$, hoang tưởng bị hại $(2 \%)$, hoang tưởng bị theo dõi $(1,0 \%)$, hoang tưởng bị chi phối $(0,7 \%)$ và hoang tưởng bị tội $(0,7 \%)$.

3. Một số yếu tố liên quan đến suy giảm nhận thức ở bệnh nhân TTPL
Bảng 3. Phân loại đánh giá rôi loạn nhận thức theo MMSE

\begin{tabular}{|c|c|c|}
\hline Mức độ & $\mathbf{n}$ & $\mathbf{\%}$ \\
\hline Không có & 52 & 17,3 \\
\hline Nhẹ & 138 & 46,0 \\
\hline Vừa & 73 & 24,3 \\
\hline Nằng & 37 & 12,3 \\
\hline
\end{tabular}

Nhận xét: Theo thang $\mathrm{MMSE}$, phần lớn nhóm tham gia nghiên cứu có rối loạn nhận thức các mức độ nhẹ, vứa, nặng chiếm tổng số $82,67 \%$. Trong đó nhóm suy giảm nhận thức mức độ nhe chiếm $46 \%$, nhóm suy giảm nhận thức vừa chiếm $24,3 \%$, nhóm suy giảm nhận thức nặng chiếm 12,3\%.

Bảng 4: Một số yếu tồ liên quan đến suy giảm nhận thức ở bệnh nhân TTPL

\begin{tabular}{|c|c|c|c|c|c|c|}
\hline \multirow{2}{*}{ Đặc điểm } & \multicolumn{2}{|c|}{ SGNT } & \multicolumn{2}{|c|}{ Không SGNT } & \multirow[b]{2}{*}{$\mathbf{p}$} & \multirow{2}{*}{$\begin{array}{c}\text { OR } \\
\text { CI95\% }\end{array}$} \\
\hline & $\mathbf{n}$ & $\%$ & $\mathbf{n}$ & $\%$ & & \\
\hline Giới tính: Nữ & 77 & 96,3 & 3 & 3,8 & \multirow{2}{*}{0,000} & 7,355 \\
\hline Nam & 171 & 77,7 & 49 & 22,3 & & $2,223-24,330$ \\
\hline Trình độ học vấn: < THPT & 182 & 88,3 & 24 & 11,7 & \multirow{2}{*}{0,000} & 0,311 \\
\hline$\geq \mathrm{THPT}$ & 66 & 70,2 & 28 & 29,8 & & $0,168-0,574$ \\
\hline \multicolumn{7}{|l|}{ Tình trạng hôn nhân } \\
\hline Không có gia đình riêng & 214 & 84,9 & 38 & 15,1 & 0,023 & 0,431 \\
\hline Có gia đình & 34 & 70,8 & 14 & 29,2 & & $(0,212-0,878)$ \\
\hline Thế bệnh: Thế di chứng & 194 & 84,3 & 36 & 15,7 & \multirow{2}{*}{0,206} & \multirow{2}{*}{ - } \\
\hline Các thế còn lại & 54 & 77,1 & 16 & 22,9 & & \\
\hline Trạng thái loạn thân: Có & 29 & 78,4 & 8 & 21,6 & \multirow{2}{*}{0,487} & \multirow{2}{*}{ - } \\
\hline Không & 219 & 83,3 & 44 & 16,7 & & \\
\hline
\end{tabular}

Nhận xét: - Bệnh nhân nữ có tỷ lệ suy giảm nhận thức cao hớn với ý nghĩa thống kê $\mathrm{p}=0,000, \mathrm{OR}=7,355$.

- Bênh nhân có trình đô họ vấn từ THPT trở lên có tỷ lệ suy giảm nhận thức thấp hơn nhóm có trình độ học vấn dưới THPT với $p=0,000$, $\mathrm{OR}=0,311$.

- bệnh nhân có gia đình có tỷ lệ suy giảm nhận thức thấp hơn nhóm còn lại (bao gồm độc thẩn, li dị/li thân, góa) có ý nghĩa thống kê với $\mathrm{p}=0,023, \mathrm{OR}=0,431$

- Thể di chứng có tỷ lệ suy giảm nhận thức coa hơn các thể còn lại nhưng không có ý nghĩa thống kê.

- Bệnh nhân không có trạng thái loạn thần có tỷ lệ suy giảm nhận thức cao hơn, tuy nhiên mức cao hơn này khồng có ý nghĩa thống kê với $\mathrm{p}=0,487$.

\section{BÀN LUẬN}

Đối tượng nghiên cứu của chúng tôi cóa lưa tuổi trung bình $48,7 \pm 9,8$ với tỷ lệ giưới nam/nữ $=2,75$, trình độ học vấn chủ yếu dưới THPT. Kết quả nghiên cứu đã cho thấy đặc điểm các triệu chứng SGNT đối tượng bệnh nhân TTPL ở trung tâm chăm sóc và nuôi dưỡng Hà Nội, trong đó với tỷ lệ suy giảm nhận thức cao, chiếm 82,7\%, chủ yếu ở mức độ nhẹ. Trong đó chúng tôi đã tìm được một số yếu tố liên quan:

- Giới tính: Trong nghiên cứu của chúng tôi, bệnh nhân nữ có tỷ lệ suy giảm nhận thức cao hớn gấp 7,355 lần với $p=0,000$. Nghiên cứ của Han và CS (2012) cho thấy bệnh nhân tâm thần phân liệt nam có suy giảm nhận thức nghiêm trọng hớn bênh nhân nữ về trí nhớ tức thời và trí nhớ gần, nhưng không có sự khác biệt về ngôn ngữ, không gian thị giác và các chỉ số chú ý [5]. Khi nghiên cứu về sứ suy giảm nhận thức trong TTPL có những đặc điểm khác biệt về giới, ví dụ như Talreja và cs (2013) kết luận bệnh nhân nam có liên quan đến suy giảm ngôn ngữ và trí nhớ hơn phụ nữ [6].

- Trình độ học vấn: Bệnh nhân có trình độ học vấn từ THPT trở lên có tỷ lệ suy giảm nhận thức ít hơn với ý nghĩa thống kê $p=0,000$, $\mathrm{OR}=0,311$. Nghiên cứu của Noel và cS (2020) cũng cho rằng số năm học càng nhiều thì khả năng suy giảm nhận thức càng ít hơn ở nhóm bệnh nhân tâm thần phân liệt [7].

- Tình trạng hôn nhân: Bệnh nhân có gia đình riêng có tỷ lệ suy giảm nhận thức ít hơn với $p=0,023, O R=0,431$. Nghiên cứu của Talreja (2013) cũng chỉ ra rằng những người không kết 
hôn có điểm số MMSE thấp hơn [6].

- Quá trình phát triển tâm thân: Bệnh nhân chậm phát triển tâm thần có tỷ lệ rối loạn nhận thức cao hơn, tuy nhiên trong nghiên cứu của chúng tôi không nhận thấy sự khác biệt có ý nghĩa thống kê.

- Triệu chứng loạn thân hiện tại: Trong nghiên cứu của chúng tôi, bệnh nhân ở trạng thái loạn thần (tức là có hoang tưởng, ảo giác) có tỷ lệ suy giảm nhận thức cao hơn, tuy nhiên không có ý nghĩa thống kê. Nghiên cứu của Talreja (2013) cũng chỉ ra mối liên quan giữa các triệu chứng dương tính và suy giảm trí nhớ được tìm thây là có ý nghĩa thống kê. Suy giảm khả năng chú ý cũng có liên quan đến các triệu chứng dương tính [6].

\section{KẾT LUẬN}

- Tỷ lệ suy giảm nhận thức ở bệnh nhân tâm thần phân liệt tương đối cao

- Bệnh nhân nữ, trình độ học vấn dưới THPT, không có gia đình riêng là các yếu tố nguy cớ của SGNT ở bệnh nhân TTPL.

\section{TÀI LIẸU THAM KHẢO}

1. McGrath J., Saha S., Chant D. và cộng sự.
(2008). Schizophrenia: a concise overview of incidence, prevalence, and mortality. Epidemiol Rev, 30, 67-76.

2. James S.L., Abate D., Abate K.H. và cộng sự. (2018). Global, regional, and national incidence, prevalence, and years lived with disability for 354 diseases and injuries for 195 countries and territories, 1990-2017: a systematic analysis for the Global Burden of Disease Study 2017. The Lancet, 392(10159), 1789-1858.

3. Vuong D.A., Van Ginneken E., Morris J., et al. (2011). Mental health in Vietnam: Burden of disease and availability of services. Asian J Psychiatry, 4(1), 65-70.

4. Charlson F.J., Ferrari A.J., Santomauro D.F. và cộng sự. (2018). Global Epidemiology and Burden of Schizophrenia: Findings From the Global Burden of Disease Study 2016. Schizophr Bull, 44(6), 1195-1203.

5. Han M., Huang X.-F., Chen D.C. và cộng sự. (2012). Gender differences in cognitive function of patients with chronic schizophrenia. Prog Neuropsy chopharmacol Biol Psychiatry, 39(2), 358-363.

6. Talreja B.T., Shah S., và Kataria L. (2013). Cognitive function in schizophrenia and its association with socio-demographics factors. Ind Psychiatry J, 22(1), 47-53.

7. Noel J., Viswanathan S.A., và Kuruvilla A. (2021). Nature and Correlates of Executive Dysfunction in Schizophrenia: An Exploratory Study. Indian J Psychol Med, 43(1), 16-23.

\title{
KẾT QUẢ PHẪU THUÂT BẮC CÂUU CHỦ VÀNH Ở BÊNH NHÂN TỪ 75 TUỔI TRỞ' LÊN TẠI BÊ̂NH VIỆN TIM HÀ NộI
}

\author{
Nguyễn Minh Ngọc*, Nguyễn Sinh Hiền*, \\ Nguyễn Thái Minh*, Nguyễn Hoàng Hà*, Hà Đức Linh*
}

\section{TÓM TẮT}

63 bệnh nhân từ 75 tuổi trở lên được phẫu thuât bắc cầu chủ vành $(B C C V)$ tại bệnh viện Tim Hà Nội trong giai đoan 2019-2020. Tuổi trung bình 78,13 \pm 3,42 tuổi (lớn nhất 88 tuổi). Nam giới chiếm 73,1\%. Euroscore II trung bình là $6,36 \%$. $38,1 \%$ có triêu chứng đau ngực năăng, $20,6 \%$ có $E F<40 \%$. Số cầu nối trung bình là 3,38 , trong đó câu nối bằng đông mạch trung bình 1,41 . Tỉ lệ tử vong sớm là 4,7\%. Thời gian theo dõi trung bình là $15,78 \pm 6,22$ tháng $(6-29$ tháng), trong thời gian theo dõi có $5 \%$ bệnh nhân tử vong là $6,7 \%$ có các biến cố tim mạch.

\section{SUMMARY \\ RESULTS OF CORONARY ARTERY BYPASS GRAFT SURGERY IN 75 YEARS AND OLDER}

\section{*Bênh viên Tim Hà Nối}

Chịu trách nhiệm chính: Nguyễn Minh Ngọc

Email: ngocnguyen89@hotmail.com

Ngày nhận bài: 28.6.2021

Ngày phản biên khoa hoc: 23.8.2021

Ngày duyệt bài: 30.8.2021

\section{PATIENTS IN HANOI HEART HOSPITAL}

In the period of 2019-2020, 63 patients from 75 years old underwent coronary bypass grafting (CABG) surgery in Hanoi Heart Hospital. Mean age 78,13 \pm 3,42 years (oldest patient was 88 years). $73,1 \%$ of case was male. Mean Euroscore II was 6,36\%. 38,1\% of patients had severe angina, 20,6\% had low EF\% $(<40 \%)$. Mean number of grafts was 3,38 , and mean arterial graft was 1,41 . Early mortality rate was $4,7 \%$. Mean follow-up time was 15,78 $\pm 6,22$ months (6-29). Mortality and cardiovascular events rate in follow-up time were $5 \%$ and $6,7 \%$.

\section{I. ĐĂT VẤN ĐỀ}

Đối với những bệnh nhân cần được phẫu thuâtt tim mach nói chung và phẫu thuât bắc cầu chủ vành (BCCV) nói riêng, mốc tuổi 75 được coi là điểm "cut-off" hợp lý để phân loại những bệnh nhân lớn tuổi, đi kèm với sự gia tăng các yếu tố nguy cơ và cần được đánh giá kỹ trước phẫu thuật ${ }^{1}$. Theo thống kê của Hội Tim Mạch Hoa Kỳ, 25\% bệnh nhân được phẫu thuật BCCV ở độ tuổi 